\title{
Hepcidin Prohormone Levels in Patients with Primary Open-Angle Glaucoma
}

\author{
Asaad A. Ghanem ${ }^{1 *}$, Salah E. Mady ${ }^{2}$, Tarek N. Attia ${ }^{2}$, Lamiaa F. Arafa ${ }^{3}$ \\ ${ }^{1}$ Mansoura Ophthalmic Center, Faculty of Medicine, Mansoura University, Mansoura, Egypt; ${ }^{2}$ Ophthalmology Department, Faculty \\ of Medicine, Banha University, Banha, Egypt; ${ }^{3}$ Department of Medical Biochemistry, Faculty of Medicine, Mansoura University, \\ Mansoura, Egypt. \\ Email: *asaadghanem@hotmail.com
}

Received December $6^{\text {th }}, 2013$; revised January $11^{\text {th }}, 2014$; accepted January $28^{\text {th }}, 2014$

Copyright (C) 2014 Asaad A. Ghanem et al. This is an open access article distributed under the Creative Commons Attribution License, which permits unrestricted use, distribution, and reproduction in any medium, provided the original work is properly cited. In accordance of the Creative Commons Attribution License all Copyrights @ 2014 are reserved for SCIRP and the owner of the intellectual property Asaad A. Ghanem et al. All Copyright (c) 2014 are guarded by law and by SCIRP as a guardian.

\section{ABSTRACT}

Aims: To assess the levels of hepcidin prohormone (Hep) in aqueous humor and plasma of human eyes with primary open-angle glaucoma (POAG) and to correlate their concentrations with the severity of glaucoma. Methods: Sixty patients with POAG and forty five patients with senile cataract (control group) were enrolled in the study prospectively. Aqueous humor samples were obtained by paracentesis from glaucoma and cataract patients who were undergoing elective surgery. Aqueous humor and corresponding plasma samples were analyzed for Hep concentrations by enzyme-linked immunosorbent assay. Results: Hep levels were significantly lower in aqueous humor of POAG patients with respect to the comparative group of cataract patients $(P<0.001)$. No significant difference in the levels of Hep in plasma of POAG and cataract patients. A positive correlation was found between plasma/aqueous humor Hep concentration in POAG versus the control group (P $<0.001)$. No significant correlation was found between Hep levels and the severity of visual field loss. Conclusion: Lower levels of aqueous humor Hep may be associated with POAG. In addition, Hep may be useful protein derivatives levels in aqueous humor of POAG patients as a consequence of glaucomatous damage.

\section{KEYWORDS}

Hepcidin Prohormone; Aqueous Humor; POAG; Cataract

\section{Introduction}

Glaucoma, which is characterized by retinal ganglion cell (RGC) apoptosis, is the prominent cause of blindness. RGC apoptosis may be the result of increased intraocular pressure, neurotoxicity and apoptosis [1], extracellular matrix (ECM) changes [2], oxidative stress [3], and hypoxia due to ocular and systemic vascular dysregulation [4].

Hepcidin prohormone (Hep) is a small peptide produced in the liver. Human Hep is produced from an 84 amino acid precursor, including a putative single peptide. Hep is an important peptide hormone that plays a critical role in the regulation of iron efflux from numerous cell types, including intestinal cells, macrophages, and hepa-

${ }^{*}$ Corresponding author. tocytes (iron homeostasis). Hep binds to and induces the degradation of ferroportin, an iron exporter expressed in specific cell types, as the receptor for this iorn-regulatory hormone. [5] The binding of hepcidin to ferroportin lesds internalization of the iron exporter with subsequent degradation in lysosomes.

Hep is responsible for iron homeostasis, decreasing iron uptake from the intestine, and release from the liver in conditions of iron overload. Conversely, Hep syntheses are decreased in iron deficiency, resulting in increased iron uptake from the intestine and release from liver stores [6].

A recent study found that Hep is expressed in Muller cells, photoreceptor cells, and retinal pigmented epithelium (RPE) in an expression pattern similar to that of ferroportin, suggesting that this transporter may play an 
obligatory role in the maintenance of iron homeostasis within the retina. Muller cells play a critical role as a support cell to retinal neurons to maintain normal retinal function. The increase in Hep expression correlates with a decrease in ferroportin expression, as well as an increase in oxidative stress and apoptosis, as would be expected from an increase in intracellular iron resulting from decreased iron export [7].

In the present study, we measured the aqueous humor and plasma levels of Hep, in patients with primary openangle glaucoma (POAG) and senile non-pathological cataract. In addition, we assessed their relation with the severity of POAG.

\section{Patients and Methods}

\subsection{Study Design}

This was a case-controlled prospective study. After explaining the details of the study, we obtained written informed consent from all patients before enrollment. The study was approved by El-Nour center for eye surgery and LASIK, trust ethics committee and was carried out in accordance with the Declaration of Helsinki (1989) of the world medical association.

\subsection{Patients}

Sixty patients with POAG whose age ranged from 51 to 70 years, were scheduled for glaucoma filtering surgery. The control group consisted of 45 non-pathological cataract patients, whose age ranged from 53 to 75 years were scheduled for cataract surgery.

Full ophthalmic examination for POAG and control subjects was done including: assessing visual acuity, slitlamp anterior and posterior segment biomicroscopy, intraocular pressure (IOP) measurement by Goldmann applanation tonometry. In addition, patients with glaucoma were subjected to gonioscopy using Goldmann three mirror contact lens, 24-2 program Humphrey visual field analyzer (Humphrey Instruments, San Leandro, CA, USA), and estimation of cup/disc ratio. A detailed medical history included age, gender, glaucoma medications, systemic hypertension, systemic medications, and previous ocular surgery or laser treatment was recorded.

Inclusion criteria were: 1) POAG patients with medically uncontrolled IOP, correlated visual field loss, and glaucomatous optic nerve head changes criteria (scheduled for trabeculectomy), 2) cataract patients had senile cataract, normal IOP and did not receive any topical medications (scheduled for phaco-emulsification), 3) systemic blood pressure measured should be systolic blood pressure $\leq 140 \mathrm{mmHg}$ and diastolic blood pressure $\leq 90$ mmHg.

The IOP measurements were measured at least five times on different times of the day from 8 AM to 5 PM.
Highest and lowest measured IOP values were used to determine IOP diurnal range. The visual field categories were: 1) normal, 2) mild, an arcuate defect, 3) moderate, abnormal in one hemifield and not within 5 degrees of fixation, and 4) severe, abnormal in both hemifields or within 5 degrees of fixation. Classification of visual field loss was done the basis of the last reliable Humphrey visual field tests before elective ocular surgery.

Exclusion criteria were: 1) patients with any type of glaucoma except POAG such as normotensive glaucoma, ocular hypertensive, angle-closure glaucoma, secondary glaucoma, pigment dispersion or exfoliation glaucoma, 2) patients with previous intraocular surgery, and laser surgery, 3) diseases that could influence Hep levels such as hepatic disease, hematological and autoimmune disorders, medications (iron preparations, chemotherapeutics agents, vitamins), and 4) patients with a family history of glaucoma were excluded from the control group.

Sixty patients with POAG were on topical anti-glaucomatous therapy classified as follow: 25\% (15 = 60) were on beta blocker, $25 \%(15=60)$ on prostaglandin analog, 30\% $(18=60)$ on carbonic anhydrase inhibitor, and $37 \%(22=60)$ on alpha agonist.

\subsection{Sample Collection}

Aqueous humor sampling: Aqueous humor samples were obtained from each patient requiring either elective glaucoma surgery or cataract surgery. Aqueous humor of $100-200 \mu$ l was collected at the beginning of surgery through a clear corneal paracentesis of the anterior chamber with a 27 gauge needle attached to a tuberculin microsyringe before any tissue manipulation. Blood contamination was meticulously avoided. Aqueous humor samples were immediately centrifuged and stored at $-20^{\circ} \mathrm{C}$ untill processing for the subsequent biochemistry techniques. All samples were protected from light.

Blood sampling: Five milliliter fasting (for at least 12 hours) venous blood samples were drawn from an antecubital vein without any anticoagulant from the participants just before operation. Each blood sample was stored in chilled tubes containing ethylene diamine tetra acetic acid ( $1 \mathrm{mg} / \mathrm{ml}$ of blood) and citrate (3.2\% Sodium citrate). The samples were centrifuged at $3000 \mathrm{rpm}$ for 5 minutes at $4^{\circ} \mathrm{C}$ and the separated plasma was rapidly frozen for storage until the time of assay.

\section{Asaay}

Hepcidin prohormone level in aqueous humor and plasma was measured by enzyme-linked immunosorbent assay (ELISA) using the DEMEDITEC GmbH (Lot: RN24429; Kiel-Wellsee, Germany) kit. This kit based on the Biotin double antibody sandwich. The prepared samples added to the standards together with second antibody labeled with biotin and ELISA solutions. Let them for 60 
minutes at $37^{\circ} \mathrm{C}$. Chromogen solution A and B added and incubated for 10 minutes at $37^{\circ} \mathrm{C}$ for color development. The absorbance measured of each well one by one under $450 \mathrm{~nm}$ wavelength, which should be carried out within the 10 minutes after having added the stop solution. According to the absorbance value of samples, the concentration of the corresponding sample calculated with special software. The range of the assay was 10 - 3000 $\mathrm{pg} / \mathrm{ml}$, the sensitivity was $5-11 \mathrm{pg} / \mathrm{ml}$.

\subsection{Statistical Analysis}

All data were analyzed with the SPSS version 16 (SPSS Inc., Chicago, IL, USA). Data were presented as mean \pm SD (standard deviation). Results were compared by using parametric unpaired t test and Chi-square $\left(\mathrm{X}^{2}\right)$ to detect any difference in either demographic or clinical characteristics. Analysis of variance (one-way ANOVA) was performed to evaluate the differences among the groups and also to adjust the variables. Spearman correlation coefficients were compared to test associations between aqueous and plasma Hep levels. Pearson correlation coefficient was used to examine the association between variables. A P-value less than 0.05 was considered to be statistically significant.

\section{Results}

One hundred and five eyes of 105 patients, age ranged from 51 to 75 years, were enrolled in the present study according to the inclusion/exclusion criteria as described. There were 60 POAG eyes (glaucoma group), and 45 non-pathologic cataract eyes (control group).

Table 1 summarizes the demographic and clinical features in studied groups. There was no statistically significant difference between the POAG group and the control group regarding age, gender and IOP $(\mathrm{P}=0.535$, $\mathrm{P}=0.416, \mathrm{P}=0.681$, respectively). As expected, cup/ disc ratio, IOP diurnal range, and mean deviation were statistically significant $(\mathrm{P}=0.011, \mathrm{P}=0.013, \mathrm{P}=0.012$, respectively).

Table 2 shows ophthalmic characteristics of glaucoma patients, such as visual acuity or cup/disc ratio. Table also includes number of glaucoma eye drops, and the severity of visual field loss were mild $(n=18)$, moderate $(n=30)$, and severe $(n=12)$.

Aqueous humor concentration of Hep was significantly lower in the POAG group when compared with that of the control group $(25.28 \pm 23.06 \mathrm{ng} / \mathrm{m} 1 \mathrm{vs} 89.21 \pm 14.25$ ng/m1, $\mathrm{P}=0.001$ ) (Figure 1 and Table 3 ).

Hep concentration in plasma of the POAG group was increased but non-statistically significant when compared with that of the control group (425.36 $\pm 123.18 \mathrm{ng} / \mathrm{ml}$ vs $392.18 \pm 142.15$ ng/l, $\mathrm{P}=0.376$ ) (Table 3 ).

A significant correlation was found between plasma/ aqueous humor Hep concentration in POAG versus the control group $(\mathrm{P}<0.001)$ (Table 4).

Table 5 shows the correlation between Hep and severity of visual field loss in glaucoma group. No significant

Table 1. Demographic and clinical features in the study and control groups.

\begin{tabular}{|c|c|c|c|}
\hline Parameters $\quad$ Group & POAG Group & Control group & ${ }^{*} \mathbf{P}$ value \\
\hline No. & 60 & 45 & \\
\hline Age (year) & $62.51 \pm 4.61$ & $61.24 \pm 3.46$ & $\begin{array}{l}F=6.56 \\
P=0.535\end{array}$ \\
\hline \multicolumn{4}{|l|}{ Gender } \\
\hline Male & $28(47 \%)$ & $22(49 \%)$ & $X^{2}=0.016$ \\
\hline Female & $32(53 \%)$ & $23(51 \%)$ & $\mathrm{P}=0.416$ \\
\hline Cup/Disc ratio & $0.71 \pm 0.16$ & $0.38 \pm 0.15$ & $\begin{array}{c}F=5.13 \\
P=0.011^{*}\end{array}$ \\
\hline IOP at time of examination & $23.6 \pm 3.5$ & $17.5 \pm 4.3$ & $\begin{array}{l}F=5.46 \\
P=0.681\end{array}$ \\
\hline IOP diurnal range ${ }^{* *}$ & $12.15 \pm 1.4$ & $6.31 \pm 2.4$ & $\begin{array}{c}F=6.64 \\
P=0.013^{*}\end{array}$ \\
\hline Mean deviation & $-8.42 \pm 2.11$ & $-3.31 \pm 0.46$ & $\begin{array}{c}F=3.61 \\
P=0.012^{*}\end{array}$ \\
\hline
\end{tabular}

No. $=$ Number, $\mathrm{F}=$ One way ANOVA test, $\mathrm{X}^{2}=$ Chi-square test. ${ }^{*}$ Significant at $\mathrm{P}<0.05 .{ }^{* *}$ IOP diurnal range is the difference between the lowest and highest recorded IOP.

Table 2. Ophthalmologic characteristics of the POAG patients, expressed as percentage.

\begin{tabular}{cccccccccccc}
\hline & \multicolumn{3}{c}{ Visual field loss } & \multicolumn{3}{c}{ No. eye drops } & \multicolumn{2}{c}{ Cup/disc ratio } & \multicolumn{2}{c}{ VA (LogMAR) } \\
\hline & Mild & Moderate & Severe & 1 & 2 & 3 & $0.1-0.5$ & $0.6-1.0$ & $0.1-0.5$ & $0.6-1.0$ \\
\hline POAG group $(\mathbf{n}=\mathbf{6 0})$ & $30 \%$ & $50 \%$ & $20 \%$ & $23 \%$ & $62 \%$ & $24 \%$ & $62 \%$ & $38 \%$ & $64 \%$ & $36 \%$ \\
\hline
\end{tabular}

No. = Number, IOP = intraocular pressure, $\mathrm{mmHg}=$ milimeter mercury, VA = visual acutiy, LogMAR = Logarithum of minumum angle of resolution. 

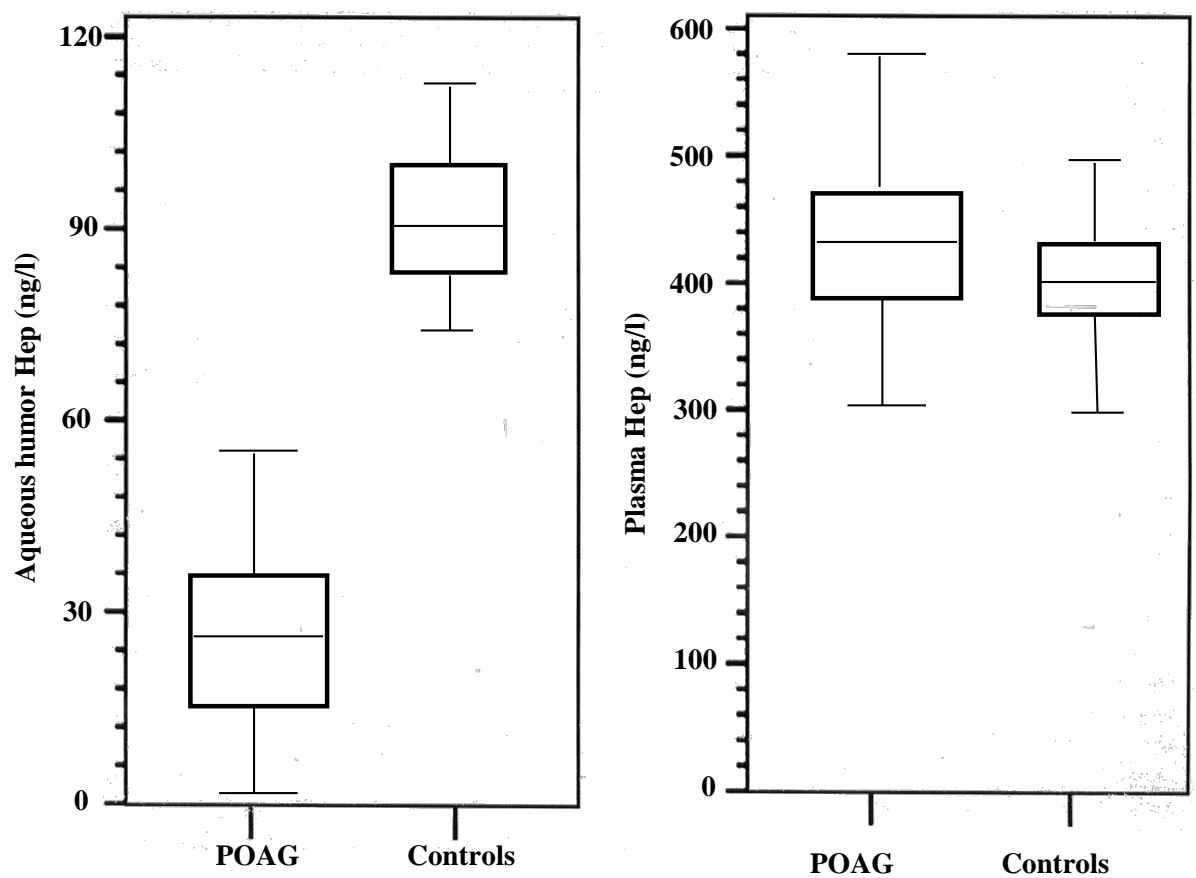

Figure 1. Descriptive analysis of hepcidin prohormone (Hep) levels in POAG and controls.

Table 3. Hepcidin prohormone (Hep) levels among the studied patients.

\begin{tabular}{ccccc}
\hline Parameter & Group & POAG Group $(\mathbf{n}=\mathbf{6 0})$ & Control Group $(\mathbf{n}=\mathbf{4 5})$ & ${ }^{*}$ P value \\
\hline Aqueous humor Hep $(\mathbf{n g} / \mathbf{m l})$ & $25.28 \pm 23.06$ & $89.21 \pm 14.25$ & $0.001^{*}$ \\
Plasma Hep $(\mathbf{n g} / \mathbf{m l})$ & $425.36 \pm 123.18$ & $392.18 \pm 142.15$ & 0.376 \\
\hline
\end{tabular}

"Significant at $\mathrm{P}<0.05$.

Table 4. Correlation between aqueous humor and plasma hepcidin prohormone (Hep) levels among the studied groups.

\begin{tabular}{ccc}
\hline Correlation between studied variables & $\mathbf{P}$ & $\mathbf{r}$ \\
\hline $\begin{array}{c}\text { Primary open-angle glaucoma } \\
\text { Hep (aqueous)-Hep (plasma) } \\
\quad \text { Control } \\
\text { Hep (aqueous)-Hep (plasma) }\end{array}$ & 0.4634 & $0.001^{*}$ \\
\hline
\end{tabular}

*Significant at $\mathrm{P}<0.05$.

Table 5. Correlation co-efficient values between severity of glaucoma stage and hepcidin prohormone (Hep) in glaucoma patients.

\begin{tabular}{cccc}
\hline Parameters & Mild V.F loss & Moderate V.F loss & Severe V.F loss \\
\hline Aqueous humor Hep (ng/ml) & & & -0.376 \\
$\mathrm{r}$ & -0.544 & -0.553 & 0.342 \\
$\mathrm{P}$ & 0.622 & 0.353 & -0.423 \\
Plasma Hep (ng/ml) & & & 0.345 \\
$\mathrm{r}$ & -0.341 & 0.327 & 0.357 \\
\hline
\end{tabular}

VF = Visual field; "Significant at $\mathrm{P}<0.05$.

correlation was found between Hep levels with mild, moderate, and severe visual field loss.

Topical therapy (beta blocker, prostaglandin analog, carbonic anhydrase inhibitor, and alpha agonist) was not associated with Hep levels in aqueous humor (t-tests; P > 0.4 in all types of topical medication). Furthermore, no 
association could be found between the Hep levels in aqueous humor and the number of topical drugs used for glaucoma therapy $(\mathrm{r}=0.651 ; \mathrm{F}=0.463 ; \mathrm{r}=0.451, \mathrm{~F}=$ 0.653 , respectively, One-way ANOVA).

\section{Discussion}

The pathogenesis underlying the development and/or progression of POAG remains unknown; there are many data that POAG is a disease involving retinal ganglion cell apoptosis [8] and abnormal extracellular matrix production [2].

In the present study, we measured the aqueous humor and plasma levels of Hep in patients with POAG and cataract (control). In addition, we correlated their concentrations with the severity of glaucoma.

Hepcidin prohormone (Hep) is a hormone central to the regulation of iron homeostasis in the body. It is believed to be produced exclusively by the liver. Ferroportin, an iron exporter, is the receptor for hepcidin. This transporter/receptor is expressed in Muller cells, photoreceptor cells, and the retinal pigment epithelium (RPE) cells within the retina [9]. In addition, the study revealed that lipopolysaccharide-induced upregulation of hepcidin and consequent down-regulation of ferroportin was associated with increased oxidative stress and apoptosis within the reina in vivo.

Iron metabolism in the eye includes the regulation of glutamate production and secretion, glutathione (GSH) synthesis, and the activity of hypoxia inducible factor-1 (HIF-1). HIF-1 has been shown to have either a clinically or experimentally mediating or contributing role in several oxygen-dependent retinal diseases such as glaucoma [10-13]. Iron catalyzed reactions have been linked to changes in lens DNA damage and cataract formation [14]. Alterations in the levels of proteins involved in iron metabolism in the neural retina of aging rodents suggest that de-regulation of the iron metabolism and the resulting accumulation of iron could be a causative factor in agerelated retinal degeneration [15]. Gnana Parksam et al. [9] found that Hep is expressed in Müller cells, photoreceptors, and RPE in an expression pattern similar to that of ferroportins.

In the present study, the concentration of Hep in the aqueous humor of the POAG group was statistically significant lower than that of the control group (25.28 \pm $23.06 \mathrm{ng} / \mathrm{m} 1$ vs $89.21 \pm 14.25 \mathrm{ng} / \mathrm{m} 1)$. This is not consistent with Sorkhabi et al. [16] revealed that the mean aqueous humor Hep concentration in eyes with POAG was significantly higher than that controls (34.55 \pm 23.01 $\mathrm{ng} / \mathrm{ml}$ versus $20.82 \pm 24.63 \mathrm{ng} / \mathrm{ml}$ ). Our study found that plasma Hep level in POAG patients were higher but non-statistically significant when compared with the controls. This findings is in agreement Sorkhabi et al.
[16].

These findings may indicate a role of Hep on the tissues that are anatomically and functionally related to the glaucomatous optic neuropathy, which consequently, induce iron metabolism de-regulation and additive deterioration. Another potential explanation of our findings is that glaucoma medication causes the concentration of Hep to be lower. A third potential explanation for our findings may be secondary to a cascade of the higher IOP levels that glaucoma patients generally have. Despite there was no statistically significant difference was found for the mean IOP of both groups in the present, it can be assumed that the worse IOP characteristics of glaucoma eyes might account for the observed differences in Hep levels.

The results of the present study suggest that local Hep secretions may have a pathogenic role in POAG. However, we did not find any correlation for Hep levels either in serum or in aqueous humor, supporting the hypothesis that the mechanism of aqueous humor Hep regulation may be independent. It must be kept in mind that some protein levels may increase in glaucoma due to disturbance in the aqueous humor outflow. Another limitation is the effect of anti-glaucomatous drugs on free radicalinduced apoptosis, as well as the possible effect of these drugs on Hep levels.

The significantly lower levels of Hep in aqueous humor associated with non-significant serum changes could be attributed to enhanced intraocular synthesis. It may be explained that the Hep levels reflect increased protein turnover, which might play a role in the pathophysiology of POAG or result from the disease process.

The non-significant correlation between Hep levels with the POAG visual field loss at any stage may indicate absence of potential secondary consequences such as ischemia, hypoxia, or reactive oxygen species caused by glaucomatous damage.

In the current study, there was significant correlation between the aqueous humor and plasma levels of Hep results suggested that levels Hep in aqueous humor were related to breakdown of blood-retinal barrier and/or ocular blood. This correlation supported that Hep may be consequence with glaucomatous damage.

In conclusion, lower aqueous levels of Hep were found in eyes with POAG, compared with controls. Also, the present study revealed that intraocular expression of Hep may be associated with optic nerve damage. Although a causal relationship cannot be established by this study, our data may indicate a link between both and the glaucomatous process, or an association between glaucoma medications and decreased aqueous levels of these peptides. Further research will be needed to elucidate the potential role of these peptides in glaucoma and other ocular diseases. 


\section{Declaration of Interests}

None of the authors has a financial or proprietary in any material or method mentioned. The authors alone are responsible for the content of the paper.

\section{Acknowledgements}

The authors thank Taha Baker for his care and diligence during writing the paper.

\section{REFERENCES}

[1] N. J. Sucher, S. A. Lipton and E. B. Dreyer, "Molecular Basis of Glutamate Toxicity in Retinal Ganglion Cells," Vision Research, Vol. 37, No. 24, 1997, pp. 3483-3493. http://dx.doi.org/10.1016/S0042-6989(97)00047-3

[2] L. Yuan and A. H. Neufeld, "Activated Microglia in the Human Glaucomatous Optic Nerve Head,” Journal of Neuroscience Research, Vol. 64, No. 5, 2001, pp. 523532. http://dx.doi.org/10.1002/jnr.1104

[3] A. A. Ghanem, L. F. Arafa and A. El-Baz, "Oxidative Stress Markers in Patients with Primary Open-Angle Glaucoma,” Current Eye Research, Vol. 35, No. 4, 2010, pp. 295-301. http://dx.doi.org/10.3109/02713680903548970

[4] G. Fuchsjäger-Mayrl, B. Wally, M. Georgopoulos, G. Rainer, K. Kircher, W. Buehl, T. Amoako-Mensah, H. G. Eichler, C. Vass and L. Schmetterer, "Ocular Blood flow and Systemic Blood Pressure in Patients with Primary Open-Angle Glaucoma and Ocular Hypertension,” Investigative Ophthalmology \& Visual Science, Vol. 45, No. 3, 2004, pp. 834-839. http://dx.doi.org/10.1167/iovs.03-0461

[5] E. Nemeth, M. S. Tuttle, J. Powelson, M. B. Vaughn, A. Donovan, D. M. Ward, T. Ganz and J. Kaplan, "Hepcidin Regulates Cellular Iron Efflux by Binding to Ferroportin and Inducing Its Internalization,” Science, Vol. 306, No. 5704, 2004, pp. 2090-2093. http://dx.doi.org/10.1126/science.1104742

[6] E. Nemeth and T. Ganz, "Regulation of Iron Metabolism by Hepcidin,” Annual Review of Nutrition, Vol. 26, 2006, pp. 323-342. http://dx.doi.org/10.1146/annurev.nutr.26.061505.111303

[7] M. Goralska, J. Ferrell, J. Harned, M. Lall, S. Nagar, L. N. Fleisher and M. C. McGahan, "Iron Metabolism in the Eye: A Review," Experimental Eye Research, Vol. 88, No. 2, 2009, pp. 204-215. http://dx.doi.org/10.1016/j.exer.2008.10.026
[8] L. A. Kerrigan, D. J. Zack, H. A. Quigley, S. D. Smith and M. E. Pease, "TUNEL-Positive Ganglion Cells in Human Primary Open-Angle Glaucoma," Archives of Ophthalmology, Vol. 115, No. 8, 1997, pp. 1031-1035. http://dx.doi.org/10.1001/archopht.1997.01100160201010

[9] J. P. Gnana-Prakasam, P. M. Martin, B. A. Mysona, P. Roon, S. B. Smith and V. Ganapathy, "Hepcidin Expression in Mouse Retina and Its Regulation via Lipopolysaccharide/Toll-Like Receptor-4 Pathway Independent of Hfe,” Biochemical Journal, Vol. 411, No. 1, 2008, pp. 79-88. http://dx.doi.org/10.1042/BJ20071377

[10] J. Narahari, R. Ma, M. Wang and W. E. Walden, “The Aconitase Function of Iron Regulatory Protein 1. Genetic Studies in Yeast Implicate Its Role in Iron-Mediated Redox Regulation," The Journal of Biological Chemistry, Vol. 275, No. 21, 2000, pp. 16227-16234. http://dx.doi.org/10.1074/jbc.M910450199

[11] M. C. McGahan, J. Harned, M. Mukunnemkeril, M. Goralska, L. Fleisher and J. B. Ferrell, "Iron Alters Glutamate Secretion by Regulating Cytosolic Aconitase Activity," American Journal of Physiology-Cell Physiology, Vol. 288, No. 5, 2005, pp. C1117-C1124. http://dx.doi.org/10.1152/ajpcell.00444.2004

[12] M. M. Zall, J. Ferrell, S. Nagar, L. N. Fleisher and M. C. McGahan, "Iron Regulates L-Cystine Uptake and Glutathione Levels in Lens Epithelial and Retinal Pigment Epithelial Cells by Its Effect on Cytosolic Aconitase,” Investigative Ophthalmology \& Visual Science, Vol. 49, No. 1, 2008, pp. 310-319. http://dx.doi.org/10.1167/iovs.07-1041

[13] M. Goralska, J. Ferrell, J. Harned, M. Lall, S. Nagar, L. N. Fleisher and M. C. McGahan, "Iron Metabolism in the Eye: A Review,” Experimental Eye Research, Vol. 88, No. 2, 2009, pp. 204-215. http://dx.doi.org/10.1016/j.exer.2008.10.026

[14] R. J. Truscott, “Age-Related Nuclear Cataract-Oxidation Is the Key,” Experimental Eye Research, Vol. 80, No. 5, 2005, pp. 709-725. http://dx.doi.org/10.1016/j.exer.2004.12.007

[15] H. Chen, B. Liu, T. J. Lukas, G. Suyeoka, G. Wu and A. H. Neufeld, "Changes in Iron-Regulatory Proteins in the Aged Rodent Neural Retina,” Neurobiology of Aging, Vol. 30, No. 11, 2009, pp. 1865-1876. http://dx.doi.org/10.1016/j.neurobiolaging.2008.01.002

[16] R. Sorkhabi, A. Ghorbanihaghjo, A. Javadzadeh, B. F. Motlagh, S. S. Ahari, “Aqueous Humor Hepcidin Prohormone Levels in Patients with Primary Open Angle Glaucoma,” Molecular Vision, Vol. 16, 2010, pp. 1832-1836. 